\title{
¿FORTALECER LA DEMOCRACIA O EL RÉGIMEN PATRIMONIAL en México? Dilemas en la esfera CiVil frente al ayuno DEL EXPRESIDENTE SALINAS
}

\section{Strengthening Democracy or the Patrimonial Regime in Mexico? Dilemmas in the Civil Sphere in the Face of Former President Salinas' Fast}

\author{
Nelson Arteaga Botello* \\ doi: https://doi.org/10.31644/ED.V8.N2.2021.A04
}

\begin{abstract}
Resumen: Se analiza la competencia por significar el ayuno que realizó el expresidente Carlos Salinas de Gortari para exigir a las autoridades que lo exoneraran de cualquier responsabilidad en las investigaciones del asesinato de Luis Donaldo Colosio — candidato presidencial del partido oficial- y de la crisis económica de 1995. El ayuno se interpretó como una ruptura de las reglas no escritas del régimen y como una amenaza a la transición democrática. La disputa sobre la autenticidad/inautenticidad del ayuno sugirió al mismo tiempo la necesidad de fortalecer la figura presidencial y acelerar el proceso de democratización.
\end{abstract}

Palabras clave: Patrimonialismo, performance, esfera civil, cargo presidencial, democracia, Salinas de Gortari.

Abstract: Drawing on the theory of the civil sphere, there are competing explanations for how to interpret the fast that former president Carlos Salinas de Gortari carried out to demand that the authorities exonerate him from any responsibility in the investigations of the murder of Luis Donaldo Colosio - presidential candidate of the official party - and the economic crisis. Fasting was interpreted as a break from the unwritten rules of the regime and as a threat to the democratic transition. The dispute over the authenticity / inauthenticity of the fast also suggested the need to strengthen the presidential figure and accelerate the democratization process.

Keywords: Patrimonialism, performance, civil sphere, presidential office, democracy, Salinas de Gortari.

* Dr. en Sociología, investigador de la Facultad Latinoamericana de Ciencias Sociales, México. ORCiD: https:// orcid.org/0000-0002-2660-7877. Correo-e: nelson.arteaga@flacso.edu.mx.

Fecha de recepción: 06/11/2020. Fecha de aceptación: 16/04/2021. Fecha de publicación: 30/07/2021.

(cc) BY-NC-ND

EntreDiversidades. Revista de Ciencias Sociales y Humanidades, Vol. 8, Núm. 2 (17), julio-diciembre 2021. Páginas: 77-98 ISSN-e: 2007-7610. https://doi.org/10.31644/ED.V8.N2.2021.A04 


\section{Introducción}

El expresidente Carlos Salinas de Gortari llamó por teléfono la noche del 2 de marzo de 1995 al noticiero "Hechos" del Canal 13 para anunciar que iniciaba un ayuno para exigir al presidente Ernesto Zedillo Ponce de León que reconociera que este no ocultó información del asesinato de Luis Donaldo Colosio - excandidato del Partido Revolucionario Institucional (PRI) a la presidencia en 1994- y no era responsable de la crisis económica del país. Y advirtió:

"estoy decidido a cambiar lo más valioso que tengo para que se aclaren estos dos temas [...] es la única manera de poder seguir saliendo adelante, así que lo más valioso que poseo, que es precisamente la vida, estoy dispuesto a darla a cambio de la verdad, a partir de este momento me mantendré en ayuno total mientras se aclaran esos temas" (Rosa, 2009).

Salinas terminó la llamada y tomó un vuelo a Nuevo León, a la casa de la señora Coronado, lideresa del Comité de Solidaridad en la colonia Fomerrey en San Bartolomé. ${ }^{1}$ El expresidente declaró el 3 de marzo: "no se me hará vivir de rodillas [con] el honor, la verdad y la dignidad, prefiero morir de pie" (Berdejo, 1995a) ante las acusaciones y vejaciones que según él estaban sufriendo familiares, amigos y antiguos colaboradores. Aunque ańadió: "hace un momento se me ha pedido que posponga por unas horas mi decisión para permitir el diálogo y resolver las injusticias que se están cometiendo" (AP Archive, 2015). Invitó a los reporteros a conocer el lugar donde ayunaba: un cuarto con una cama, dos banderas de México — una en la mesa de noche y otra al pie de su cama-, un librero con juguetes y varias fotografías suyas con líderes de los Comités de Solidaridad (AP Archive, 2015). Posteriormente, viajó a la ciudad de México para reunirse con Zedillo. Según la revista Proceso, en la reunión estuvieron Pedro Aspe - Secretario de Hacienda del gobierno salinista - y el expresidente Miguel de la Madrid — quien había designado a Salinas como sucesor en 1987- (Proceso, 1995). De regreso a Fomerrey, Salinas anunció que "había signos alentadores" para un acuerdo. El 4 de marzo suspendió el ayuno tras hablar con Arturo Warman — Secretario de la Reforma Agraria—, quien le aseguró que se atenderían sus exigencias. Salinas reiteró así su respeto y apoyo al presidente. Días después, la Procuraduría General de la República (PGR) anunció que Salinas no era investigado, y el expresidente inició un exilio que lo llevó a Boston, La Habana, Montreal y Dublín.

El ayuno se interpretó como una alteración de las reglas no escritas del régimen que establecía que los expresidentes debían guardar silencio y abstenerse de intervenir en la vida política (salvo a solicitud del presidente). Estas reglas permitieron la sucesión pacífica del poder ejecutivo por décadas. Si, como sugiere Balandier (1994), el cargo presidencial representaba la fuerza gravitacional del orden como simbólico de la política, el ayuno se leyó como un desafío a esa fuerza.

El artículo analiza la competencia por el control del sentido en el ayuno del expresidente en el ámbito de la esfera civil, ese mundo de valores e instituciones que "genera la capacidad de crítica social e integración democrática al mismo tiempo" (Alexander, 2006: 4). La esfera civil está organizada a través de discursos: palabras que expresan opiniones, marcan distancias,

${ }^{1}$ Comités creados por el Programa Nacional de Solidaridad para combatir la pobreza en el país.

EntreDiversidades. Revista de Ciencias Sociales y Humanidades, Vol. 8, Núm. 2 (17), julio-diciembre 2021. Páginas: 77-98 ISSN-e: 2007-7610. https://doi.org/10.31644/ED.V8.N2.2021.A04 
provocan desplazamientos y organizan lo que existe y lo que puede existir (Farge, 1994). Los discursos respaldan o cuestionan a aquellos actores sociales que requieren algún reconocimiento, la reparación de un daño o la satisfacción de una demanda.

Estas acciones pueden ser interpretadas desde la sociología cultural como performances —acciones simbólicas donde los actores establecen su posición sobre su situación en la sociedad (Alexander y Mast, 2011)_. Los performances pueden incluir bloqueo de caminos, marchas, huelgas de hambres, autoinmolaciones o dańos a la propiedad (Smith, 2005). Son juzgados por los discursos en la esfera civil, ya sea como expresiones auténticas — legítimas de grupos y personaso inauténticas — las cuales se consideran más un montaje falso de carácter ilegítimo- (Alexander y Stack, 2019). Un performance auténtico muestra una fusión de sus elementos dramáticos que hace que parezca verosímil, mientras que uno de carácter inauténtico manifiesta una de-fusión de sus elementos, como algo no verosímil, a tal punto que es posible ver las costuras simbólicas que intentan sostenerlo, haciendo parecer falso.

El ayuno de Salinas puede ser considerado como un performance o drama que expresó la ruptura de las reglas del régimen posrevolucionario. Sus efectos se leyeron: 1) como una oportunidad para la democracia; 2) como un acto que produciría caos social; y, 3) como un intento por dar a Salinas un poder por encima de la figura presidencial. Algunos discursos sugirieron a Zedillo que reactivara los poderes más autoritarios de su cargo — incluso para asegurar la transición democrática-, mientras que otros sugirieron acelerar el proceso de democratización.

Para analizar estas interpretaciones, el artículo abre con una exposición de los conceptos básicos que permiten comprender la competencia de los discursos por significar el ayuno de Salinas. Se presenta a continuación el contexto histórico que fue traído a cuenta en la disputa simbólica por el ayuno. Posteriormente, se analiza si el ayuno fue significado como performance auténtico o inauténtico. En las conclusiones, se hace una reflexión sobre cómo el ayuno del expresidente contribuyó a definirlo como la bête noire que condensa hasta hoy en día la impureza de la política nacional.

\section{La esfera civil, códigos patrimoniales y performances}

La esfera civil se organiza a través de los discursos que los actores se imputan entre sí para acusarse de poseer o no las atribuciones civiles o anti-civiles — de pureza o impureza democrática (Jacobs, 1996)_. Esto permite establecer los límites morales con los que se definen los procesos de inclusión o la exclusión social en las democracias. El carácter puro o impuro que se atribuyen los actores es relacional: la civilidad de unos se articula en el lenguaje de la incivilidad de los otros (Alexander, 2006). Las disputas sobre las atribuciones morales se cristalizan espacial y temporalmente en las instituciones comunicativas y regulativas de la esfera civil. Según Kivisto y Sciortino (2015), entre las primeras se encuentran los medios de comunicación, las asociaciones voluntarias y los movimientos sociales, las cuales reflejan y difunden las posturas, pasiones e intereses de quienes se asumen como parte de una sociedad y que hablan en nombre de la sociedad, hacia la sociedad y como sociedad. Entre las instituciones regulativas están los cargos electivos y los tribunales, los cuales responden a los reclamos sociales y poseen el derecho de tomar decisiones vinculantes.

EntreDiversidades. Revista de Ciencias Sociales y Humanidades, Vol. 8, Núm. 2 (17), julio-diciembre 2021. Páginas: 77-98 ISSN-e: 2007-7610. https://doi.org/10.31644/ED.V8.N2.2021.A04 
Las imputaciones sobre las virtudes civiles y anti-civiles que se atribuyen entre sí los actores transcurren en tres niveles: los motivos, las relaciones y las instituciones (Alexander, 2006). En el primero, se considera que un actor social o político está respaldado por motivos democráticos si se interpreta que es autónomo, racional, razonable y realista; y se estima que es un actor antidemocrático si se juzga que sus motivos son irracionales, no realistas o carecen de autonomía. En un segundo nivel, se evalúan las relaciones de los actores sociales o políticos en términos civiles si se estima que son abiertas, susceptibles a crítica, honorables y confiables; y son calificadas como anti-civiles si se evalúan como cerradas, sospechosas, condescendientes, egoístas o tramposas. En tercer nivel, se valoran las instituciones a las que apelan los actores, y se categorizan como civiles si se interpreta que están reguladas por la ley, son equitativas, inclusivas e impersonales; o como anti-civiles, si se valora que funcionan de manera arbitraria, jerárquica, excluyente y para beneficio de una persona o grupo. ${ }^{2}$

Las atribuciones civiles o anti-civiles que se asignan los actores pueden incluir imputaciones que hacen referencia a formas de solidaridad social no-democráticas. Baiocchi (2006) mostró cómo en Brasil el discurso civil se confronta con el de las instituciones corporativas — que perciben la dependencia, el tutelaje y el clientelismo como positivos_- Por su parte, Tognato (2011) mostró cómo en Colombia el discurso democrático compite con el de la hacienda — que evalúa positivamente la relación armónica entre el patrón y el peón subordinado- Esta competencia de solidaridades produce esferas civiles parciales porque el conflicto entre pureza civil e impureza anti-civil está entrelazado con otros códigos (Alexander, 2015).

En México existen códigos, discursos e instituciones de carácter patrimonial que se caracterizan por la presencia de normas consuetudinarias que: 1) permiten el ejercicio del poder de forma autoritaria y discrecional; 2) proporcionan una amplia autonomía de negociación fuera del marco de la ley; y, 3) cultivan relaciones de patronazgo (Arzuaga y Arteaga, 2019; Levy, 2020). Esto produce una burocracia que percibe la administración del Estado como un instrumento para beneficios de intereses particulares (Adler-Lomnitz, Salazar y Adler, 2004). Sin embargo, el patrimonialismo tiene reglas que operan bajo principios tradicionales dentro de una compleja fábrica de leyes, una burocracia diferenciada y líderes políticos especializados (Weber, 1979 [1922]). Así, los líderes y la burocracia patrimonialistas se ven desacreditados a los ojos de los gobernados si no reconocen los límites consuetudinarios y el ejercicio discrecional del poder, pero también se les desacredita cuando son incapaces de contener sus pasiones o anteponer las normas consuetudinarias al marco legal si se considera necesario.

En el caso de México, "el presidente de la república ha sido la figura política clave que condensa el poder patrimonial del sistema político y encarna simbólicamente el centro de la política mexicana" (Meyer, 1976: 243). El ayuno de Salinas fue interpretado tanto en el campo patrimonial y en el civil como una violación de las reglas no escritas de dicho régimen. El primer campo exigió a Zedillo revigorizar la figura presidencial —incluso para asegurar la transición democrática - mientras que el segundo requirió desmontar el régimen y fortalecer la democracia.

${ }^{2}$ Esta forma binaria esquemática revela el esqueleto a través del cual las sociedades construyen las narrativas que guían su acción y permiten ubicar cómo se construyen procesos de inclusión y exclusión social (Alexander, 2006).

EntreDiversidades. Revista de Ciencias Sociales y Humanidades, Vol. 8, Núm. 2 (17), julio-diciembre 2021. Páginas: 77-98 ISSN-e: 2007-7610. https://doi.org/10.31644/ED.V8.N2.2021.A04 
Así, el ayuno puede ser considerado como un performance político: una acción simbólica a través de la cual Salinas estableció su posición frente a lo que consideró una afrenta política que ponía en riesgo su estatus de exmandatario. Como todo performance, estuvo sujeto a interpretación. Cuando un performance recibe respaldo es porque ha sido valorado como auténtico; es decir, resulta creíble o legítimo — expresa el carácter genuino de una demanda-. Mientras que es objeto de crítica o rechazo cuando se estima que es inauténtico; en otras palabras, se ve como una puesta en escena falsa que no expresa dramáticamente lo que el actor está tratando de representar (Alexander y Bartmanski, 2012; Mercier, 2005). Aunque el ayuno de Salinas fue juzgado como inauténtico por los distintos campos de interpretación, el expresidente hizo un esfuerzo dramático para que resultara auténtico a los ojos de la audiencia. El concepto de autenticidad e inautenticidad es relacional, por tanto, para comprender cómo se define una u otra evaluación es necesario comprender cuál es su estructura relacional.

\section{Metodología}

Para examinar esta disputa por el sentido del performance de Salinas, se analizó el debate en las instituciones comunicativas de la esfera civil, particularmente en la prensa. Se revisaron 121 columnas políticas publicadas en los periódicos Excélsior, El Universal, El Sol de México, Reforma y La Jornada. ${ }^{3}$ La crónica periodística es una interpretación sobre un acontecimiento anclado en referentes morales y, por tanto, son valoraciones sesgadas (Río, 2008). Este sesgo es fundamental para el análisis, ya que en él se construyen mensajes que traducen situaciones concretas a través de evaluaciones y narraciones (Breese y Luengo, 2016).

¿Cómo se leyeron las interpretaciones del ayuno en las columnas periodísticas? Primero, se identificaron las imputaciones que cada columna hizo a los motivos, relaciones e instituciones que Salinas puso en juego en su performance con el fin de determinar si se consideraba un acto auténtico o inauténtico —es decir, legítimo o ilegítimo, creíble o no creíble—. Para ello, fue necesario examinar cuáles son las características de autenticidad e inautenticidad que se expresan discursivamente en las columnas. Posteriormente, se clasificaron las mismas a partir de los juicios que hicieron sobre el impacto del performance en el régimen político y a la incipiente democracia. Después, se dio cuenta en qué medida los columnistas demandaron la reactivación o supresión del régimen patrimonial, así como la democratización del país.

\section{Las reglas no escritas de los expresidentes}

A decir de Falcón (2015), la dictadura de Porfirio Díaz (1890-1910) estableció por primera vez reglas de carácter consuetudinario, clientelista y corporativo de alcance nacional. No obstante, la dictadura centró la legitimidad de su poder en la persona de Díaz y no en el cargo presidencial (Aguilar, 1994). Cuando las presiones políticas y sociales contra el régimen se incrementaron, la persona y el cargo — que eran uno solo- perdieron rápidamente legitimidad (Womack, 2017).

${ }^{3}$ El periodo de la disputa fue entre el 28 febrero y el 15 de marzo de 1995.

EntreDiversidades. Revista de Ciencias Sociales y Humanidades, Vol. 8, Núm. 2 (17), julio-diciembre 2021. Páginas: 77-98 ISSN-e: 2007-7610. https://doi.org/10.31644/ED.V8.N2.2021.A04 
La revolución de 1910 acabó con la dictadura, pero tardó tiempo en crear las instituciones para separar el cargo de la persona que lo ocupaba (Meyer, 1993). A decir de Beezley (2007), los generales vencedores -Álvaro Obregón y Plutarco Elías Calles - tuvieron que enfrentar revueltas campesinas, grupos del antiguo régimen y generales revolucionarios que se sentían desplazados del nuevo orden político. Sin embargo, Álvaro Obregón (1920-1924) logró mantener el control del Ejército e impulsó algunas reformas de orden social que permitieron cierta estabilidad política. Calles (1924-1928) siguió la misma estrategia.

Gracias a la derogación del artículo constitucional que prohibía la reelección, Obregón logró acceder a un nuevo periodo presidencial (1928-1932) (Buchenau, 2006). No obstante, fue asesinado y Calles tomó el control del país como "jefe máximo" de la herencia revolucionaria. Fundó el Partido Nacional Revolucionario (PNR) en 1929 y restituyó la no reelección en la constitución. Como jefe máximo articuló a los líderes revolucionarios en el PNR. Calles se convirtió en el poder detrás del cargo presidencial. Todo cambió con la designación del general Lázaro Cárdenas como candidato del PNR y posterior presidente de la república.

Cárdenas (1936-1940) exilió del país a Calles en 1936. Para ello, primero vinculó a los campesinos y los trabajadores al Estado a través del partido heredero del PNR, el Partido de la Revolución Mexicana (PRM) en 1938 (Hernández, 1994). Al dejar la presidencia, Cárdenas estableció las reglas que dieron estabilidad política al país por años (Magrini, 2019): a) el presidente designaba a su sucesor, el cual se convertía en el candidato del partido oficial y después en presidente (Langston, 2017); b) el presidente en turno perdía todo su poder cuando la investidura era transmitida al gobernante entrante (Cosío, 1975); y, c) el expresidente debía guardar silencio y asumir la responsabilidad de los problemas que enfrentara el nuevo presidente (Weldon, 1997). Como señaló el expresidente Adolfo Ruiz Cortines (1952-1958): una vez que se deja el cargo se "tiene como primer deber respetar al que es y evidenciar absoluta disciplina" (Krauze, 1999). ${ }^{4}$

Cárdenas consolidó la separación de la persona del cargo presidencial y, además, afianzó el régimen patrimonial. Así, se estableció uno en el que a cambio de satisfacer las demandas de la población y dar una salida corporativa a las exigencias de representación, se exigía el respeto a la figura presidencial y a sus decisiones, por autoritarias que fueran (Zabludovsky, 1989). De esta manera, se reclamó una obediencia casi total de los medios de comunicación, las asociaciones civiles y los partidos políticos de oposición. Las elecciones se mantenían bajo el control del Estado, así como la interpretación de la ley, y la Constitución quedaba sujeta al poder discrecional del presidente y la estructura política de gobernadores y jueces designados por él.

El PRM se transformó en el PRI en 1946 y comenzó a operar como un aparato político disciplinado a través del cual el presidente — como líder de facto- gobernaba las Cámaras de Diputados y de Senadores durante los seis años que duraba su mandato (Nacif, 2004). Mientras

\footnotetext{
${ }^{4}$ Los expresidentes tuvieron cargos honorarios en distintos gobiernos. Por ejemplo, Cárdenas fue Secretario de Guerra y Marina y posteriormente supervisó proyectos hidrológicos. Miguel Alemán Valdés (1946-1952) encabezó el Consejo Nacional de Turismo. Adolfo Ruiz Cortines la Nacional Financiera. Adolfo López Mateos (1958-1964) el Comité Organizador de los juegos Olímpicos. Gustavo Díaz Ordaz (1964-1970) fue embajador en España, mientras que Luis Echeverría (1970-1976) de la UNESCO y representante de México en Nueza Zelanda y Australia. Miguel de la Madrid (1982-1988) dirigió el Fondo de Cultura Económica.
}

EntreDiversidades. Revista de Ciencias Sociales y Humanidades, Vol. 8, Núm. 2 (17), julio-diciembre 2021. Páginas: 77-98 ISSN-e: 2007-7610. https://doi.org/10.31644/ED.V8.N2.2021.A04 
que el PRI garantizaba la institucionalidad en el tiempo, el eje gravitacional que condensaba el orden era la figura del presidente de la República (Balandier, 1994). No obstante, fue desafiada en distintos momentos. En los años sesenta campesinos, sindicatos, estudiantes y otros grupos de la clase media demandaron mayor participación democrática (Hernández, 1994). En los setenta el régimen experimentó una de sus primeras crisis morales (Loaeza, 2013), sobre todo durante el gobierno de Luis Echeverría (1970-1976), quien buscó restablecer la figura de la “jefatura máxima”. El incremento en los precios internacionales del petróleo permitió a su sucesor — José López Portillo (1976-1982) — una mayor capacidad de negociación con distintos grupos sociales (Sanderson, 1983) e impulsar una reforma política (Rodríguez, 2010).

Cuando los precios del petróleo se desplomaron, la economía entró en una de las crisis más graves en la historia del país. Así, el presidente eligió al que había sido hasta entonces su secretario de programación y presupuesto, Miguel de la Madrid (1982-1988), quien al llegar a la presidencia inició la "revolución pasiva" al neoliberalismo en México (Morton, 2003). Las políticas neoliberales minaron la legitimidad del régimen patrimonial porque no podía responder a las demandas de los grupos corporativos del PRI ni de la población en general (Sheppard, 2011). Esta tensión se cristalizó en las primeras críticas al régimen en las urnas (Craig y Cornelius, 1995). El PRI tuvo sus primeras derrotas electorales y disenso interno más significativo en los ochenta. ${ }^{5}$

\section{El salinismo}

Cuando Miguel de la Madrid se disponía a elegir a su sucesor, militantes del PRI —encabezados por Cuauhtémoc Cárdenas, hijo del general Lázaro Cárdenas - renunciaron al PRI al no encontrar en su interior ninguna interlocución (Magaloni, 2006; Garrido, 1993). Los disidentes encabezados por Cárdenas formaron el Frente Democrático Nacional (FDN) con otros partidos y compitieron contra el candidato del PRI Carlos Salinas de Gortari —elegido por de la Madridy Manuel Clouthier, del Partido Acción Nacional (PAN).

La disputa por la presidencia de 1988 fue la más competida hasta ese momento, aun cuando el Estado controlaba las instituciones electorales, los recursos económicos y los medios para alterar los resultados (Peritore y Galve-Peritore, 1993). Así, los medios de coacción política y su cultura autoritaria en su morfología más definida se pusieron a operar (Adler-Lomnitz y Melnik, 2000). Cuando los primeros votos llegaron a la autoridad electoral - encabezada por el secretario de Gobernación-, aquellos favorecían al FDN. Esto inquietó al presidente, quien ordenó detener el conteo de votos (Cantú, 2019). Su decisión se interpretó como una estrategia para favorecer a Salinas, quien al final del conteo obtuvo 50\% de los votos; Cárdenas, 31\% y Clouthier, 17\%. El FDN y el PAN se movilizaron para protestar, pero sus diferencias los distanciaron (Gómez, 1990). No obstante, la elección de 1988 desgastó también el régimen patrimonial.

De este modo, Salinas buscó reactivar la legitimidad del régimen: desplegó la autoridad consuetudinaria del cargo e impulsó acuerdos políticos con distintos actores, incluso de la oposición. Por ejemplo, acordó con el PAN promover un proyecto de apertura democrática y económica, a cambio de que ese partido lo reconociera como presidente. En los siguientes meses

${ }^{5}$ Hubo disensos al interior del PRI con anterioridad, pero no acabaron formando una oposición visible electoralmente.

EntreDiversidades. Revista de Ciencias Sociales y Humanidades, Vol. 8, Núm. 2 (17), julio-diciembre 2021. Páginas: 77-98 ISSN-e: 2007-7610. https://doi.org/10.31644/ED.V8.N2.2021.A04 
su gobierno detuvo a líderes sindicales (Arriaga, 2015), ejecutivos de la bolsa (Edel y Edel, 1988), exfuncionarios públicos (Freije, 2015) y narcotraficantes (Lupsha, 1991), con el fin de mostrar que tenía el control político del país.

El régimen reconoció el triunfo del PAN en Baja California en julio de 1989 —convirtiéndose en la primera entidad no gobernada por el PRI durante el siglo XX (López, 2001) —. En contraste, mostró su autoritarismo contra el Partido de la Revolución Democrática (PRD) — que nació de las fuerzas integrantes del FDN- (Lucardi, 2016). En materia económica, se fortaleció el proyecto neoliberal (Hoshino, 1996; Clifton, 2000). Salinas lanzó el Programa Nacional de Solidaridad (PRONASOL) para atender a los grupos más pobres y marginados a través de esquemas de corresponsabilidad con el fin de crear infraestructura social (Moreno-Brid, Pardinas y Ros, 2009; Yaschine, 1999). La intención era copiar prácticas de las organizaciones civiles para direccionarlas a favor del régimen (Fox y Hernández, 1992). Para algunos, el PRONASOL modernizó las estructuras clientelares del régimen patrimonial (Nilsen, 2012; Diaz-Cayeros y Magaloni, 2003). Salinas logró con estas y otras acciones consolidar su imagen en la opinión pública: para 1993 el 81\% de la población respaldaba su gestión. A fin de ese año designó a su sucesor, Luis Donaldo Colosio.

No obstante, 1994 habría de ser un año turbulento: el primero de enero el Ejército Zapatista de Liberación Nacional (EZLN) se levantó en Chiapas, además, Colosio fue asesinado, y en septiembre José Francisco Ruiz Massieu — Secretario General del PRI—. Salinas afrontó estos hechos con cuestionables resultados frente a los actores políticos y la opinión pública. Con respecto al EZLN, el gobierno inició la negociación de paz después de muchos titubeos y ataques a las comunidades indígenas de Chiapas. Finalmente, el 16 de febrero el EZLN anunció el inicio de las conversaciones. En marzo presentó una lista de demandas y el gobierno propuso una serie de modificaciones. El 22 del mismo mes el EZLN anunció que iniciaría una consulta a sus bases sobre los resultados del diálogo. Todo se interrumpió un día después, cuando fue asesinado Colosio.

La muerte de Colosio tuvo varias interpretaciones. Se dijo que el EZLN había legitimado la violencia como forma de intervención política. También se responsabilizó a la prensa por señalar insistentemente que Colosio era un mal candidato. Asimismo, se dijo que el neoliberalismo generó las condiciones políticas para que ocurriera el crimen. Independientemente de estas lecturas, la conclusión era que la muerte de Colosio representaba el fin del pacto posrevolucionario y la unidad del PRI — fracturado por la pugna entre políticos y tecnócratas—. ${ }^{6}$ Cuando Salinas montó guardia frente a los restos de Colosio en la sede nacional del PRI, fue increpado con gritos de “justicia, justicia!”, “¡Colosio sí, Camacho, no!”, “ “¿Quién fue, quién fue?!”, “¿Que no se archive, que vuelen cabezas!”.

\footnotetext{
${ }^{6}$ Las teorías de la conspiración aparecen cuando los asesinos de políticos son considerados "marginales" o "innobles", comparados con la supuesta "nobleza” y "grandeza" de sus víctimas, por lo que el asesino aparece como la tuerca de un complejo engranaje de intereses (Eyerman, 2011).

${ }^{7}$ Camacho Solís estuvo en la lista de sucesión. Cuando fue descartado, manifestó públicamente su inconformidad, lo cual fue mal visto por la opinión pública. Salinas lo nombró canciller y posteriormente Comisionado para la Paz en Chiapas, lo que desató el rumor de que sustituiría a Colosio.
}

EntreDiversidades. Revista de Ciencias Sociales y Humanidades, Vol. 8, Núm. 2 (17), julio-diciembre 2021. Páginas: 77-98 ISSN-e: 2007-7610. https://doi.org/10.31644/ED.V8.N2.2021.A04 
Un día después del funeral de Colosio, el presidente convocó a sindicalistas, gobernadores, secretarios, diputados y senadores del PRI a una reunión con el fin de elegir al nuevo candidato. A través de una supuesta consulta abierta a los liderazgos del PRI, se designó a Zedillo (García y Figueiras, 2006). Si con esta reunión la figura presidencial mantuvo su fuerza como fuente de sentido simbólico, algo estaba fracturado. La opacidad y desaseo de las investigaciones sobre Colosio incrementaron el cisma en el régimen. Pese a todo, el PRI ganó las elecciones, gracias a una campańa centrada en advertir que el país se sumiría en el caos si ganaba el PAN o el PRD.

Cuando Zedillo recibió el aval de su triunfo de la autoridad electoral, afirmó: "quiero un partido fortalecido en su independencia frente al Estado". Era la primera vez que una autoridad política hacia este tipo de declaraciones (Pichardo, 2001). Como operador de este proyecto, designó al secretario general del PRI, José Francisco Ruiz Massieu, coordinador de la bancada de su partido en la Cámara de Diputados. ${ }^{8}$ Este último fue asesinado el 28 de septiembre de 1994. Su muerte tuvo varias interpretaciones, resultado de la pugna entre demócratas y autoritarios al interior del grupo en el poder o entre autoritarios tanto de perfil tecnocrático como tradicional. Salinas designó al hermano de la víctima - Mario Ruiz Massieu- como encargado de la investigación. Este último acusó a miembros del PRI de cometer el crimen, asegurando que hubo una operación concertada que involucraba a destacados miembros del PRI, por lo que pidió a Zedillo hacer todo lo posible para aclarar el crimen de su hermano (CFEMEDOMEX, 2011).

En este contexto de acusaciones mutuas entre los miembros del grupo en el poder, Zedillo juró como presidente el 1 de diciembre de 1994. En su discurso inaugural llamó a firmar un acuerdo de paz con el EZLN y se comprometió a esclarecer los asesinatos de Colosio y Ruiz, porque dichos crímenes, a su entender, planteaban dudas a los mexicanos sobre la continuidad de las instituciones. Para ello, encargó al procurador de justicia - Antonio Lozano Graciaencabezar una comisión para tal efecto (500 años de México en documentos, 1994).

\section{La crisis política del régimen}

En el ámbito económico, Zedillo decretó la libre flotación del peso frente al dólar para afrontar una serie de problemas económicos. La decisión provocó la devaluación acelerada del peso, que perdió la mitad de su valor en una semana. El gobierno de Zedillo fue objeto de duras críticas, pero este último aseguró que su decisión resolvería problemas económicos heredados del gobierno anterior, sin mencionar directamente a Salinas. ${ }^{9}$ Este último respondió que la devaluación no era su responsabilidad y acusó al gobierno de filtrar la decisión de la libre flotación a un grupo de empresarios. Salinas bautizó la iniciativa como el "error de diciembre". Su declaración rompió la norma de los expresidentes de guardar silencio y asumir la responsabilidad de los problemas que heredaban. El conflicto escaló cuando Lozano Gracia anunció que Raúl Salinas -hermano del expresidente- era el autor intelectual del asesinato de Ruiz. Además, Gracia dejó ver entre líneas

\footnotetext{
${ }^{8}$ Ruiz estuvo casado con una hermana de Salinas.

${ }^{9}$ A partir de López Portillo (1976-1982) cada nuevo gobierno encarceló a miembros del gabinete saliente por actos de corrupción o abuso de autoridad.

EntreDiversidades. Revista de Ciencias Sociales y Humanidades, Vol. 8, Núm. 2 (17), julio-diciembre 2021. Páginas: 77-98 ISSN-e: 2007-7610. https://doi.org/10.31644/ED.V8.N2.2021.A04
} 
que el exmandatario ocultó información sobre la muerte de Colosio. ${ }^{10}$ Salinas anunció entonces su ayuno. ¿Cómo fue interpretada esta acción?

Líderes, representantes populares y expresidentes del PRI señalaron que el ayuno no significaba una fractura al interior del partido, sino expresaba diferencias entre el presidente entrante y saliente (Reforma, 1995; Noriega, 1995; Romero J., 1995; Herrera, 1995). Sugirieron a este último que planteara en privado su inconformidad, la cual consideraron respetable pero no respaldaban (Noriega, 1995; La Jornada, 1995b). Los gobernadores del PRI indicaron que Salinas debía evitar cualquier acción impropia para un exmandatario que creara confusión entre los mexicanos (Ramírez, Gajeda y Ruiz, 1995).

Mariano Palacios Alcocer — líder y diputado federal del PRI — consideró que Salinas debía guardar silencio (Herrera, 1995). El expresidente López Portillo consideró que Salinas debía ser prudente, servir a México y "aguantar vara" (Cabello, 1995; El Sol de México, 1995a; Excélsior, 1995d). El resto de los expresidentes juzgó que Salinas tenía el compromiso de guardar silencio y servir a su sucesor (Berdejo, 1995a). Los exfuncionarios del gobierno salinista —algunos laborando en el nuevo gobierno - invitaron al expresidente a cambiar de actitud y dieron su apoyo a Zedillo como presidente y líder moral del PRI (Navarreto y Ortiz, 1995). Así, hubo un llamado generalizado de los priistas para que Salinas se ajustara a las reglas no escritas del régimen.

Los partidos de oposición advirtieron que el expresidente debía abandonar el país porque al romper las reglas no escritas se convertía en una amenaza para el régimen, la democracia y el sistema de justicia (El Sol de México, 1995a; Arroyo, 1995; Catón, 1995d). Porfirio Muñoz Ledo - presidente del PRD— señaló que Salinas tenía una relación patológica con el poder y no entendía que ya no era presidente (Morales, S., 1995a; Rodríguez, R., 1995). Cuauhtémoc Cárdenas agregó que la confrontación Zedillo/Salinas ponía en riesgo al país (Ortiz, Álvarez e Irizar, 1995). El PAN acusó al expresidente de estar enfermo de poder (Morales, S., 1995c; Romero, I., 1995; Palacios, 1995; Mejía, et al., 1995; Hernández y Méndez, 1995). Incluso, la Conferencia del Episcopado Mexicano solicitó al expresidente dejar a un lado su protagonismo por el bien del país (Tavarés, 1995; Guarneros, 1995).

\section{Reglas rotas y personalidad irracional}

En las columnas políticas se suscribió que el ayuno expresaba la pugna al interior del grupo gobernante, lo que ponía al país al borde de la desestabilización política (Rodríguez, C., 1995; La Jornada, 1995a; Alemán, 1995; Samaniego, 1995; García, G., 1995; Excélsior, 1995b; Loret, 1995; Labastida, 1995; Méndez, 1995; Romero J., 1995; Musacchio, 1995; Granados, 1995). Se dijo que la ruptura inició cuando Salinas acusó a Zedillo del "error de diciembre", se agravó con la detención de Raúl y el rumor de que el expresidente ocultó información del caso Colosio (Manzanilla, 1995; Catón, 1995d). Se expuso que Salinas mostró inmadurez política al romper el código de silencio de los expresidentes que garantizaba la paz social del país (Morales, S., 1995b; Mejido, 1995b). Las columnas políticas trajeron a cuenta que ese código lo impuso Lázaro Cárdenas, lo que ayudó a cohesionar políticamente la nación (Mejido, 1995a;

\footnotetext{
${ }^{10}$ El artículo no busca saber si la responsabilidad del conflicto fue de Zedillo o Salinas, sino mostrar cómo se interpretó el ayuno y sus posibles efectos.
}

EntreDiversidades. Revista de Ciencias Sociales y Humanidades, Vol. 8, Núm. 2 (17), julio-diciembre 2021. Páginas: 77-98 ISSN-e: 2007-7610. https://doi.org/10.31644/ED.V8.N2.2021.A04 
Avilés, 1995; Excélsior, 1995d; Granados, 1995; Musacchio, 1995). Ahora que la regla se violó — aseguraba el periodista Granados (1995) — el país entraba en el caos. El escritor Carlos Fuentes (1995) argumentó que esperaba que "la diosa de las tinieblas, Coatlicue" no se impusiera en la lucha Zedillo/Salinas, ensangrentado al país.

El ayuno ponía en riesgo al mismo tiempo el régimen patrimonial y a la incipiente democracia (Mena, 1995; Mejido, 1995a; El Sol de México, 1995b; La Jornada, 1995a). Para algunos comentaristas, Salinas rompió la regla, ya sea porque quería o sabía que era obsoleta (Blancarte, 1995). Así, buscaba extender su poder más allá de su sexenio (Loret, 1995; Excélsior, 1995e). No obstante, también se juzgó el ayuno como un acto irracional. Se argumentó que Salinas era un megalómano (Torres, 1995; Avilés, 1995; García, G., 1995; Loret, 1995; Cremoux, 1995). No soportaba dejar de ser el "amo y señor" del país (Avilés, 1995; Moya, 1995). Estaba "borracho de poder" (Carranca, 1995; Reyes, 1995). No podía controlarse emocionalmente (Rodríguez, 1995a; García, L., 1995). Estaba fuera de sí (Mejido, 1995a), enojado por la detención de su hermano (Cárdenas, 1995a). Marcado por el dolor, terminó por hacer el ridículo (Martínez, 1995; Manzanilla, 1995; Samaniego, 1995). Al ver que lo que construyó se caía, buscó convertirse en un "nuevo Gandhi” para chantajear al presidente (Moiron, 1995; Cárdenas, 1995a; Excélsior, 1995b; Castañeda, 1995). Se dijo que Salinas quería mostrarse como víctima del autoritarismo que él mismo ejerció, incluso más allá de las reglas del régimen presidencialista (Torres, 1995; Excélsior, 1995b).

Se advirtió que su desequilibrio mental lo llevó a montar una "parodia", "farsa" o "caricatura teatral", que lo hizo ver como "tonto" (Michel, 1995; Garza, 1995; Garduño y Carrizales, 1995; Reyes, 1995; Excélsior, 1995a; Sánchez, 1995). Montó una "tragicomedia” o "drama ridículo" en una colonia del PRONASOL para demandar protección, influir en la vida política, así como evadir la ley y los juicios morales en su contra (Covián, 1995; Díaz, 1995). Su ayuno había que interpretarlo, se dijo, al mismo tiempo como un "drama griego", "tragedia familiar", "lucha dinástica", "choque de colosos" y "telenovela". Era una obra mal montada de Macbeth, "una historia contada por un idiota, llena de sonido y furia que no significa nada" (Reyes, 1995: 12). Su "teatrito" lo expuso al escarnio (Sánchez, 1995). Alguien debería recordarle a Salinas que ya murió como rey y otro monarca ocupa el trono (Musacchio, 1995).

Salinas pasará a la historia como el presidente más odiado y no como el gran transformador, se señaló (Ícaro, 1995). Una encuesta publicada en Excélsior mostró el supuesto juicio de la opinión pública al expresidente: $66 \%$ rechazaba su actitud y $58 \%$ que debía de quedarse callado (Excélsior, 1995f), mientras que el New York Times afirmó que Salinas no tendría ese lugar brillante que él esperaba en la historia de su país (El Universal, 1995a).

\section{Fortalecer la presidencia, Maximato o democracia}

Frente al ayuno, el campo patrimonialista conminó a Zedillo a mostrar que el poder presidencial no se comparte, se ejerce (Mejido, 1995a; Cárdenas, 1995a). Se le exigió castigar al hermano del expresidente (Rodríguez, C., 1995; Cárdenas, 1995a) y asegurarse que Salinas no participó en la muerte de Colosio y Ruiz (El Sol de México, 1995a; Reyes, 1995; Manzanilla, 1995; Pereztrejo, 1995; Arroyo, 1995). No obstante, desde el campo civil se le sugirió no comportarse según las

EntreDiversidades. Revista de Ciencias Sociales y Humanidades, Vol. 8, Núm. 2 (17), julio-diciembre 2021. Páginas: 77-98 ISSN-e: 2007-7610. https://doi.org/10.31644/ED.V8.N2.2021.A04 
reglas del presidencialismo y el régimen, porque estaba en juego el destino del país y no el de un grupo político (Sánchez, 1995).

Al terminar el ayuno, estos dos campos compitieron por el sentido de los acuerdos entre Zedillo y Salinas. Uno, los interpretó como un logro del presidente; el otro, como un éxito del expresidente. Desde el campo patrimonial, la primera interpretación afirmó que Zedillo usó las normas consuetudinarias del régimen; así, la institución presidencial salió fortalecida (Avilés, 1995; Berdejo, 1995d). El presidente mostró que tenía el control del país (Rodríguez, 1995b; González, 1995); ahora debía depurar el gobierno y al PRI construyendo una nueva unidad política a su alrededor (Pavón, Ramírez y Moreno, 1995; Hernández y Méndez, 1995). La sociedad debía, por su parte, respaldar ampliamente al presidente (El Sol de México, 1995b; Rodríguez, 1995a).

Desde el campo civil se afirmó que Zedillo ganó la partida porque dejó atrás las reglas consuetudinarias y se guío por las normas democráticas (Excélsior, 1995c). Se dijo que el presidente evitó la tentación autoritaria, lo cual era saludable para la incipiente democracia (Loret, 1995; Blancarte, 1995; Berdejo, 1995b; Manzanilla, 1995). Ahora, debía abandonar el neoliberalismo y permitir al Estado controlar la economía (Moya, 1995; Labastida, 1995). Pero, sobre todo, debía transformar el sistema político: "ese tejido de lealtades, valores, equilibrios, beneficios, complicidades y compromisos que dieron al país estabilidad sin democracia" (Musacchio, 1995: 7). El actual gobierno tenía que alejarse del PRI y desmantelar la presidencia imperial para evitar cualquier futuro desplante autoritario (El Universal, 1995b; Berdejo, 1995c; La Jornada, 1995c; Sodi, 1995; Reyes, 1995; Excélsior, 1995b).

Los discursos que sugirieron que Salinas impuso su voluntad, señalaron que Zedillo optó por un mal arreglo a un buen pleito político, aunque perdiera legitimidad (Morales, R., 1995; Cremoux, 1995). Zedillo fue derrotado y puso a las instituciones de justicia al servicio de Salinas (Rascón, 1995; Catón, 1995c). Se argumentó que cedió a las presiones de Salinas porque - a diferencia de la disputa entre Cárdenas y Calles - no contaba con un proyecto popular que lo respaldara (Rascón, 1995). Al ceder a la presión Zedillo permitió que Salinas se convirtiera en el "jefe máximo" — como Calles en su momento (Catón, 1995a y 1995b; Cárdenas, 1995b)—. Al expresidente le bastó con un ayuno para que la PGR asegurara que no encubrió ningún hecho criminal, se dijo (Cárdenas, 1995b). Por tanto, el hecho mostró que Zedillo era sensible al escándalo, Salinas lo sabía y actuaba por encima del presidente (Hernández, 1995).

\section{Performance inauténtico}

El ayuno fue traducido por las columnas políticas desde los códigos civil y patrimonial como una fractura de las reglas no escritas del régimen. Cada uno advirtió que esto afectaba las atribuciones simbólicas y materiales de la figura presidencial. Ambos campos lo percibieron como una amenaza a la estabilidad política y al orden social, alterando el horizonte esperado de comportamiento de otros actores políticos. Si el expresidente abandonó los acuerdos establecidos, esto podía ser interpretado como una invitación para romper otras reglas, generando incertidumbre. El mayor riesgo era que el país retrocediera al tiempo donde imperaba el desorden o el poder de un "jefe máximo".

EntreDiversidades. Revista de Ciencias Sociales y Humanidades, Vol. 8, Núm. 2 (17), julio-diciembre 2021. Páginas: 77-98 ISSN-e: 2007-7610. https://doi.org/10.31644/ED.V8.N2.2021.A04 
La regresión política venía —a los ojos de los actores políticos y los medios de comunicaciónde un expresidente que tenía una agenda estratégica definida o que estaba atrapado en sus emociones. Quienes apostaron por el primer tipo de interpretación, dibujaron a Salinas como un ser maquiavélico, con un plan perfectamente diseńado para erosionar el cargo presidencial y tener un espacio en la política nacional. Aquellos que subrayaron el carácter irracional de su acción, consideraron que su obsesión por el poder o la afectación emocional que sufrió por las acusaciones a su hermano introdujeron contingencia en las reglas consuetudinarias.

Estas interpretaciones sobre los motivos del expresidente hicieron ver el ayuno, tanto en el campo civil como en el patrimonial, como un performance inauténtico, un montaje, y no como la expresión legítima de una demanda que resultara creíble y justa. Quienes valoraron el componente estratégico de Salinas resaltaron el cuidado con el cual escogió la casa, decoró su recámara y se vistió. Según esta interpretación, todo era un escenario artificial, claramente ficticio, creado con el fin de demostrar el poder político y moral que tenía. Para aquellos que atribuyeron a Salinas un comportamiento irracional, la puesta en escena pretendía resaltar su papel como víctima de un poder que lo desprestigiaba injusta y arbitrariamente. De modo que, según el primer tipo de interpretación, Salinas buscaba extender su poder más allá de su sexenio, y para el segundo tipo de lectura, buscaba evadir la ley. En ambos casos el performance del expresidente afectaba las instituciones y códigos patrimoniales.

Si bien el ayuno del expresidente fue calificado como inauténtico, un montaje teatral falso, tenía efectos reales en la vida política. Para el campo patrimonial era importante mantener la fuerza simbólica del presidente, y así poder garantizar la continuidad del régimen e incluso permitir la transición democrática. La figura presidencial era necesaria porque — desde esta lectura - era la garantía de la estabilidad política. Para el campo civil, el hecho de que se hubieran alterado las reglas consuetudinarias abría la puerta para transformar el sistema político y evitar cualquier restauración autoritaria. Por tanto, para este campo, no importaba si Salinas actuó racional o irracionalmente, era necesario cambiar el régimen patrimonial.

\section{Conclusiones}

Las interpretaciones expresadas en las columnas de opinión sobre el ayuno de Salinas —en tanto performance- cuestionaron la legitimidad del drama del expresidente, así como sus exigencias políticas. Hubo quienes llamaron a reforzar la figura presidencial como un referente de unidad política —independientemente de si se apostaba por robustecer el régimen autoritario o una transición democrática en el largo plazo - y quienes aprovecharon para implorar la aceleración de la democratización del país. Cuando el ayuno se suspendió, fue interpretado por unos como un acto que fortalecía los poderes del presidente Zedillo y, por otros, que los debilitaba, convirtiendo a Salinas en un nuevo jefe máximo — como lo había sido en su tiempo Calles-.

El ayuno de Salinas acabó por definir su perfil como uno de los políticos más controvertidos de la historia reciente de México, al que se le atribuye desde entonces un enorme poder de influencia en la vida política, económica y social. El desaseo en las investigaciones de los casos Colosio y Ruiz, su manejo de la crisis en Chiapas, el impulso al proceso de liberalización del

EntreDiversidades. Revista de Ciencias Sociales y Humanidades, Vol. 8, Núm. 2 (17), julio-diciembre 2021. Páginas: 77-98 ISSN-e: 2007-7610. https://doi.org/10.31644/ED.V8.N2.2021.A04 
país, su ejercicio autoritario del poder, así como su cuestionado triunfo electoral en las elecciones presidenciales de 1988, lo convirtieron en la representación de la impureza civil, capaz de mover los hilos de la política a voluntad, más allá de las instituciones e independientemente de los grupos políticos. Si bien Salinas no se volvió el nuevo "jefe máximo", se convirtió en el referente simbólico del mal dentro de la política mexicana, no solo para los grupos opositores, sino incluso para una parte de la clase política alrededor del PRI, quienes consideran que su ayuno minó significativamente la fuerza simbólica del cargo presidencial y fue responsable en parte de que el partido perdiera el poder solo cinco años después.

\section{Bibliografía citada}

500 años de México en documentos (1994). Discurso de Toma de Posesión de Ernesto Zedillo Ponce de León como Presidente de los Estados Unidos Mexicanos [en línea]. Disponible en: http://www.biblioteca.tv/artman2/publish/1994 60/Discurso de Toma de Posesi n de Ernesto Zedillo Po 70.shtml (Consultado el 14 de marzo de 2021).

Adler-Lomnitz, Larissa y Melnik, Ana (2000). Chile's Political Culture and Parties, An Anthropological Explanation. Notre Dame, United States of America: University of Notre Dame.

Adler-Lomnitz, Larissa, Rodrigo Salazar e Ilya Adler (2004). Simbolismo y ritual en la política mexicana. México: Siglo XXI.

Aguilar, Luis (1994). "El liberalismo social del presidente Salinas de Gortari: una interpretación”. Revista Mexicana de Ciencias Politicas y Sociales [en línea], 39 (156), pp. 189-221. doi: http://dx.doi.org/10.22201/fcpys.2448492xe.1994.156.49956 (Consultado el 27 de abril de 2021).

Alexander, Jeffrey (2006). The Civil Sphere. Oxford, United Kingdom: Oxford University Press. Alexander, Jeffrey (2015). "Nine Thesis on The Civil Sphere", en Kivisto, Peter y Sciortino, Giuseppe (eds.). Solidarity, Justice, and Incorporation: Thinking through the Civil Sphere. Oxford, United Kingdom: University Press, pp. 172-189.

Alexander, Jeffrey y Bartmanski, Dominik (2012). "Materiality and Meaning in Social Life: Toward an Iconic Turn in Cultural Sociology”, en Alexander, Jeffrey, Dominik Bartmanski y Bernhard Giesen (eds.). Iconic Power: Morality and Meaning in Social Life. Nueva York, United States of America: Palgrave MacMillan, pp. 1-12.

Alexander, Jeffrey y Mast, Jason (2011). "Introduction: Symbolic Action in Theory and Practice: The Cultural Pragmatics of Symbolic Action”, en Alexander, Jeffrey (ed.). Performance and Power. Cambridge, United Kingdom: Cambridge University Press, pp. 7-24.

Alexander, Jeffrey y Stack, Trevor (2019). "Introduction: On Radicalism and The Civil Order", en Alexander, Jeffrey, Trevor Stack y Farhad Khosrokhavar (eds.). Breaching the Civil Order: Radicalism and the Civil Sphere. Cambridge, United Kingdom: Cambridge University Press, pp. 1-10.

EntreDiversidades. Revista de Ciencias Sociales y Humanidades, Vol. 8, Núm. 2 (17), julio-diciembre 2021. Páginas: 77-98 ISSN-e: 2007-7610. https://doi.org/10.31644/ED.V8.N2.2021.A04 
Arriaga Lemus, María de la Luz (2015). “The Mexican Teachers' Movement: Thirty Years of Struggle for Union Democracy and the Defense of Public Education”. Social Justice [en línea], 42 (3/4-142), pp. 104-117. Disponible en: https://www.jstor.org/stable/24871329 (Consultado el 6 de octubre de 2020).

Arzuaga Magnoni, Javier y Arteaga Botello, Nelson (2019). "Batallas simbólicas del Estado en México: la disputa por el Zócalo y la ceremonia del Grito de Independencia”, en Arteaga Botello, Nelson y Tognato, Carlo (eds.). Sociedad, Cultura, y Esfera Civil: Una Agenda de Sociología Cultural. México: Facultad Latinoamericana de Ciencias Sociales, pp. 29-66.

Associated Press (AP) Archive (2015). Mexico: Former President Salinas Calls off Hunger Strike [video]. Disponible en: https://www.youtube.com/watch?v=3PII]NDItpY (Consultado el 6 de noviembre de 2020).

Baiocchi, Gianpaolo (2006). "The Civilizing Force of Social Movements: Corporate and Liberal Codes in Brazil's Public Sphere". Sociological Theory [en línea], 24 (4), pp. 285-311. doi: https://doi.org/10.1111/j.1467-9558.2006.00292.x (Consultado el 27 de abril de 2021).

Balandier, Georges (1994). El poder en escenas. México: Paidós.

Beezley, William (2007). "Reflections on the Historiography of Twentieth-Century Mexico". History Compass [en línea], 5 (3), pp. 963-974. doi: https://doi.org/10.1111/j.1478_ 0542.2007.00433.x (Consultado el 7 de octubre de 2020).

Breese, Elizabeth Butler y Luengo, María (2016). "Conclusion: News Innovation and Enduring Commitments”, en Alexander, Jeffrey, Elizabeth Butler Breese y María Luengo (eds.). The Crisis of Journalism Reconsidered. Cambridge, United Kingdom: Cambridge University Press, pp. 282-290. doi: https://doi.org/10.1017/CBO9781316050774.017 (Consultado el 27 de abril de 2021).

Buchenau, Jürgen (2006). Plutarco Elías Calles and the Mexican Revolution. Maryland, United States of America: Rowman \& Littlefield.

Cantú, Francisco (2019). “The Fingerprints of Fraud: Evidence from Mexico’s 1988 Presidential Election”. American Political Science Review [en línea], 113 (3), pp. 710-726. doi: https:// doi.org/10.1017/S0003055419000285 (Consultado el 6 de octubre de 2020).

CFEMEDOMEX (2011). Los demonios andan sueltos [video]. Disponible en: https://www. youtube.com/watch? $=101$ YAJ85L4 (Consultado el 14 de marzo de 2021).

Clifton, Judith (2000). "On the Political Consequences of Privatisation: The Case of Telefonos De Mexico”. Bulletin of Latin American Research [en línea], 19 (1), pp. 63-79. Disponible en: https://ssrn.com/abstract=1597756 (Consultado el 14 de marzo de 2021).

Cosío Villegas, Daniel (1975). La sucesión presidencial. México: Joaquín Mortiz.

Craig, Ann y Cornelius, Wayne (1995). "Houses Divided: Parties and Political Reform in Mexico", en Mainwaring, Scott y Scully, Timothy (eds.). Building Democratic Institutions: Party Systems in Latin America. Stanford, California, United States of America: Standford University Press, pp. 249-97.

EntreDiversidades. Revista de Ciencias Sociales y Humanidades, Vol. 8, Núm. 2 (17), julio-diciembre 2021. Páginas: 77-98 ISSN-e: 2007-7610. https://doi.org/10.31644/ED.V8.N2.2021.A04 
Diaz-Cayeros, Alberto y Magaloni, Beatriz (2003). The Politics of Public Spending - Part II. The Programa Nacional de Solidaridad (PRONASOL) in Mexico. México: Banco Mundial. Disponible en: https://documents.worldbank.org/en/publication/documents-reports/ documentdetail/529521468773406296/the-politics-of-public-spending-part-iithe-programa-nacional-de-solidaridad-pronasol-in-mexico (Consultado el 27 de abril de 2021).

Edel, Candace y Edel, Matthew (1988). "Mexico's Economic Crisis: The Impact of the 'Pact". Review of Radical Political Economics [en línea], 20 (2\&3), pp. 247-252. doi: https://doi.org/10.1177/048661348802000237 (Consultado el 14 de marzo de 2021).

Eyerman, Ron (2011). The Cultural Sociology of Political Assassination: From MLK and RFK to Fortuyn and Van Gogh. London, United Kingdom: Palgrave MacMillan.

Falcón, Romana (2015). El jefe político. Un dominio negociado en el mundo rural del Estado de México, 1856-1911. México: El Colegio de México, El Colegio de Michoacán, Centro de Investigaciones y Estudios Superiores en Antropología Social.

Farge, Arlette (1994). Subversive Words: Public Opinion in Eighteenth Century in France. Cambridge, United Kingdom: Polity.

Fox, Jhonatan y Hernández, Luis (1992). "Mexico’s Difficult Democracy: Grassroots Movements, NGOs, and Local Government”. Alternatives: Global, Local, Political [en línea], 17 (2), pp. 165-208. Disponible en: http://www.jstor.org/stable/40644738 (Consultado el 14 de marzo de 2021).

Freije, Vanessa (2015). "Exposing Scandals, Guarding Secrets: Manuel Buendía, Columnismo, and the Unraveling of One-Party Rule in Mexico, 1965-1984". The Americas [en línea], 72 (3), pp. 377-409. doi: https://doi.org/10.1017/tam.2015.30 (Consultado el 1 de octubre de 2020).

García Calderón, Carola y Figueiras Tapia, Leonardo (2006). Medios de Comunicación y Campañas Electorales (1988-2000). México: Universidad Nacional Autónoma de México, Plaza y Valdés.

Garrido, Javier (1993). La Ruptura. La Corriente Democrática del PRI. México: Grijalbo.

Gómez Tagle, Silvia (1990). Las estadisticas electorales de la reforma politica. México: El Colegio de México. doi: https://doi.org/10.2307/j.ctv6mtc4x (Consultado el 27 de abril de 2021).

Hernández Chávez, Alicia (1994). "Mexican Presidentialism: A Historical and Institutional Overview". Mexican Studies [en línea], 10 (1), pp. 217-225. doi: https://doi.org/10.2307/1051972 (Consultado el 10 de octubre de 2020).

Hoshino, Taeko (1996). "Privatization of Mexico's Public Enterprises and the Restructuring of the Private Sector". The Developing Economies [en línea], 34 (1), pp. 34-60. doi: https:// doi.org/10.1111/j.1746-1049.1996.tb00728.x (Consultado el 14 de marzo de 2021).

Jacobs, Ronald (1996). "Civil Society and Crisis: Culture, Discourse, and the Rodney King Beating”. American Journal of Sociology [en línea], 101 (5), pp. 1238-1272. Disponible en: https://www.jstor.org/stable/2782354 (Consultado el 2 de octubre de 2020).

EntreDiversidades. Revista de Ciencias Sociales y Humanidades, Vol. 8, Núm. 2 (17), julio-diciembre 2021. Páginas: 77-98 ISSN-e: 2007-7610. https://doi.org/10.31644/ED.V8.N2.2021.A04 
Kivisto, Peter y Sciortino, Giuseppe (2015). "Introduction: Thinking through The Civil Sphere”, en Kivisto, Peter y Sciortino, Giuseppe (eds.). Solidarity, Justice and Incorporation. Oxford, United Kingdom: Oxford University Press, pp. 1-30. doi: https://doi.org/10.1093/ acprof:oso/9780199811908.001.0001 (Consultado el 27 de abril de 2021).

Krauze, Enrique (1999). El sexenio de Ruiz Cortines. Ciudad de México, México: Editorial Clío. Langston, Joy (2017). Democratization and Authoritarian Party Survival. Oxford, United Kingdom: Oxford University Press.

Levy, Eldad (2020). "Legacy Work: Three Strategies of Adversarial Meaning-making of Historical Characters”. American Journal of Cultural Sociology [en línea]. doi: https://doi. org/10.1057/s41290-019-00095-6 (Consultado el 7 de octubre de 2020).

Loaeza, Soledad (2013). "Dos hipótesis sobre el presidencialismo autoritario". Revista Mexicana de Ciencias Politicas y Sociales [en línea], 58 (218), pp. 53-72. doi: http://dx.doi.org/10.1016/S0185-1918(13)72289-X (Consultado el 7 de octubre de 2020).

López Guzmán, Cuauhtémoc (2001). "La alternancia política en Baja California: hacia un nuevo equilibrio de poderes”. Estudios Fronterizos [en línea], 2 (3), pp. 41-62. Disponible en: https://www.redalyc.org/articulo.oa?id=53020302 (Consultado el 14 de marzo de 2021).

Lucardi, Adrián (2016). "Building Support From Below? Subnational Elections, Diffusion Effects, and the Growth of the Opposition in Mexico, 1984-2000". Comparative Political Studies [en línea], 49 (14), pp. 1855-1895. doi: https://doi.org/10.1177/0010414016666857 (Consultado el 9 de octubre de 2020).

Lupsha, Peter (1991). "Drug Lords and Narco-corruption: The Players Change But the Game Continues". Crime, Law and Social Change [en línea], Vol. 16, pp. 41-58. doi: https:// doi.org/10.1007/BF00389737 (Consultado el 9 de octubre de 2020).

Magaloni, Beatriz (2006). Voting for Autocracy: Hegemonic Party Survival and Its Demise in Mexico. Cambridge, United Kingdom: Cambridge University Press. doi: https://doi. org/10.1017/CBO9780511510274 (Consultado el 27 de abril de 2021).

Magrini, Ana (2019). "Populismo y revolución en México: reflexiones en torno a los lenguajes políticos durante los años setenta”. Revista Historia Autónoma [en línea], Núm. 14, pp. 195212. doi: https://doi.org/10.15366/rha2019.14.010 (Consultado el 9 de octubre de 2020).

Mercier, Arnaud (2005). "Efficacité du performatif dans les rituels politiques". Hermès, La Revue [en línea], Núm. 43, pp. 31-37. doi: https://doi.org/10.4267/2042/23987 (Consultado el 12 de octubre de 2020).

Meyer, Lorenzo (1976). "La Encrucijada”, en Meyer, Lorenzo, et al. (eds.). Historia General de México: Vol. 4. Edición 2, edición corregida. México: El Colegio de México, pp. 201-284. doi: https://doi.org/10.2307/j.ctvt1shx5 (Consultado el 27 de abril de 2021).

Meyer, Lorenzo (1993). "El presidencialismo. Del populismo al neoliberalismo". Revista Mexicana de Sociología [en línea], 55 (2), abril-junio, pp. 57-81. doi: https://doi.org/10.2307/3541102 (Consultado el 27 de abril de 2021).

EntreDiversidades. Revista de Ciencias Sociales y Humanidades, Vol. 8, Núm. 2 (17), julio-diciembre 2021. Páginas: 77-98 ISSN-e: 2007-7610. https://doi.org/10.31644/ED.V8.N2.2021.A04 
Moreno-Brid, Juan, Juan Pardinas Carpizo y Jaime Ros Bosch (2009). "Economic Development and Social Policies in Mexico". Economy and Society [en línea], 38 (1), pp. 154-176. doi: https://doi.org/10.1080/03085140802560652 (Consultado el 4 de noviembre de 2020).

Morton, Adam (2003). 'Structural Change and Neoliberalism in Mexico: 'Passive Revolution' in the Global Political Economy”. Third World Quarterly [en línea], 24 (4), pp. 631-653. Disponible en: https://www.jstor.org/stable/3993429 (Consultado el 14 de marzo de 2021).

Nacif, Benito (2004). "Las relaciones entre los poderes ejecutivo y legislativo tras el fin del presidencialismo en México”. Política y Gobierno [en línea], 11 (1), pp. 9-41. Disponible en: http://www.politicaygobierno.cide.edu/index.php/pyg/article/view/338 (Consultado el 14 de marzo de 2021).

Nilsen, Alf (2012). "Revolution and State in Modern Mexico: The Political Economy of Uneven Development, by Adam David Morton. Book Review”. Capital \& Class, 36 (3), pp. 559562. doi: https://doi.org/10.1177/0309816812461063d (Consultado el 8 de septiembre de 2020).

Peritore, Patrick y Galve-Peritore, Ana (1993). "Cleavage and Polarization in Mexico's Ruling Party: A Field Study of the 1988 Presidential Election”. The Journal of Developing Areas [en línea], 28 (1), pp. 67-88. Disponible en: https://www.jstor.org/stable/4192294 (Consultado el 12 de septiembre de 2020).

Pichardo Pagaza, Ignacio (2001). Triunfos y Traiciones: Crónica Personal, 1994. México: Océano. Río, Manuel (2008). "Usos y abusos de la prensa como fuente de datos sobre las acciones colectivas". Revista de Metodología de Ciencias Sociales [en línea], Núm. 16, juliodiciembre, pp. 59-84. doi: https://doi.org/10.5944/empiria.16.2008.1390 (Consultado el 14 de marzo de 2021).

Rodríguez Araujo, Octavio (2010). "The Emergence and Entrenchment of a New Political Regime in Mexico". Latin American Perspectives [en línea], 37 (1), pp. 35-61. doi: https:// doi.org/10.1177/0094582X09355428 (Consultado el 13 de septiembre de 2020).

Rosa, Ernesto de la (2009). telenoticias los salinas [video]. Disponible en: https://www.youtube. com/watch?v=JNUwujv1AMk (Consultado el 6 de noviembre de 2020).

Sanderson, Steven (1983). "Presidential Succession and Political Rationality in Mexico". World Politics [en línea], 35 (3), pp. 315-334. doi: https://doi.org/10.2307/2010156 (Consultado el 14 de marzo de 2021).

Sheppard, Randal (2011). "Nationalism, Economic Crisis and 'Realistic in Revolution' in 1980s Mexico". Nations and Nationalism [en línea], 17 (3), pp. 500-519. doi: https://doi. org/10.1111/j.1469-8129.2010.00472.x (Consultado el 14 de marzo de 2021).

Smith, Philip (2005). Why War? The Cultural Logic of Iraq, the Gulf War, and Suez. Chicago, United States of America: University of Chicago Press.

EntreDiversidades. Revista de Ciencias Sociales y Humanidades, Vol. 8, Núm. 2 (17), julio-diciembre 2021. Páginas: 77-98 ISSN-e: 2007-7610. https://doi.org/10.31644/ED.V8.N2.2021.A04 
Tognato, C. (2011). "Extending trauma across cultural divides: On kidnapping and solidarity in Colombia”, en Alexander, Jeffrey, Ron Eyerman y Elizabeth Breese (eds.). Narrating Trauma: Studies in the Contingent Impact of Collective Suffering. Boulder, United States of America: Paradigm Publishers, pp. 191-212.

Weber, Max (1979 [1922]). Economía y Sociedad. México: Fondo de Cultura Económica.

Weldon, Jeffrey (1997). “The Political Sources of Presidentialism in Mexico”, en Mainwaring, Scott y Shugart, Matthew (eds.). Presidentialism and Democracy in Latin America. Nueva York, United States of America: Cambridge University Press, pp. 225-258. También disponible en: https://doi.org/10.1017/CBO9781139174800

Womack, John (2017). Zapata y la revolución mexicana. México: Fondo de Cultura Económica. Yaschine, Iliana (1999). "The Changing Anti-Poverty Agenda. What Can the Mexican Case Tell Us?”. IDS Bulletin [en línea], 20 (2), pp. 47-60. doi: https://doi. org/10.1111/j.1759-5436.1999.mp30002006.x (Consultado el 14 de marzo de 2021).

Zabludovsky, Gina (1989). “The Reception and Utility of Max Weber's Concept of Patrimonialism in Latin America”. International Sociology [en línea], 4 (1), pp. 51-66. doi: https://doi. org/10.1177/026858089004001004 (Consultado el 14 de marzo de 2021).

\section{Hemerografía citada}

A-Avilés Randolph, Jorge (1995). "Por la palabra, libres. La capacidad de asombro". El Sol de México, 4 de marzo de 1995, sec. A, p. 16.

Berdejo Arvizu, Aurora (1995a). "Frentes políticos". Excélsior, 3 de marzo de 1995, p. 1 y 20.

Berdejo Arvizu, Aurora (1995b). "Frentes políticos”. Excélsior, 4 de marzo de 1995, p. 1 y 22.

Berdejo Arvizu, Aurora (1995c). "Frentes políticos". Excélsior, 5 de marzo de 1995, p. 1 y 30.

Berdejo Arvizu, Aurora (1995d). "Frentes políticos". Excélsior, 6 de marzo de 1995, p. 1 y 30.

Blancarte, Roberto (1995). “¿Hay justicia en la política?”. La Jornada, 6 de marzo de 1995, p. 5.

Cabello, Yolanda (1995). "Ser prudente y servir a México, la función de un ex presidente, señala López Portillo". El Universal, 3 de marzo de 1995, p. 1 y 9.

Cárdenas Cruz, Francisco (1995a). "Pulso político". El Universal, 3 de marzo de 1995, p. 1 y 2. Cárdenas Cruz, Francisco (1995b). "Pulso político”. El Universal, 6 de marzo de 1995, p. 1 y 2. Carranca y Rivas, Raúl (1995). "La tragedia del poder”. El Sol de México, 6 de marzo de 1995, sec. A, p. 9 y 18.

Castañeda, Jorge (1995). "Nadie pudo imaginar tan desastroso final para el 'Milagro Salinista”. Excélsior, 9 de marzo de 1995, sec. A, p. 31.

Catón (1995a). "Cedió Zedillo". Reforma, 6 de marzo de 1995, p. 8.

Catón (1995b). "De política... y cosas peores”. El Sol de México, 6 de marzo de 1995, sec. A, p. 3.

Catón (1995c). "Los chistes de Salinas". Reforma, 4 de marzo de 1995, p. 7.

Catón (1995d). "Ostracismo a Carlos Salinas”. Reforma, 2 de marzo de 1995, p. 6.

Covián Pérez, Miguel (1995). "El precio". La Jornada, 5 de marzo de 1995, p. 11.

Cremoux, Raúl (1995). "Chantaje y megalomanía”. Excélsior, 7 de marzo de 1995, sec. A, p. 7 y 8. Díaz Garza, Felipe (1995). "Los desfiguros de Salinas”. Reforma, 4 de marzo de 1995, p. 5.

EntreDiversidades. Revista de Ciencias Sociales y Humanidades, Vol. 8, Núm. 2 (17), julio-diciembre 2021. Páginas: 77-98 ISSN-e: 2007-7610. https://doi.org/10.31644/ED.V8.N2.2021.A04 
El Sol de México (1995a). "Demanda que se aclare que él no está involucrado en el asesinato de Colosio". El Sol de México, 3 de marzo de 1995, sec. A, p. 3.

El Sol de México (1995b). "Unidad y legalidad". El Sol de México, 4 de marzo de 1995, sec. A, p. 9.

El Universal (1995a). "No tendrá CSG el lugar que esperaba en la historia: The New York Times”. El Universal, 7 de marzo de 1995, p. 4.

El Universal (1995b). “¿Reforma o lucha estéril?”. El Universal, 4 de marzo de 1995, p. 6 y 13.

Excélsior (1995a). “Críticas a Salinas”. Excélsior, 4 de marzo de 1995, p. 6.

Excélsior (1995b). "El presidente y el ex presidente. Posdata”. Excélsior, 3 de marzo de 1995, p. 10.

Excélsior (1995c). "México es hoy un país de paz". Excélsior, 5 de marzo de 1995, p. 14.

Excélsior (1995d). "Papel de un ex presidente". Excélsior, 3 de marzo de 1995, p. 6.

Excélsior (1995e). “Pobre!”. Excélsior, 6 de marzo de 1995, p. 5 y 19.

Excélsior (1995f). "Repudió 64\% de mexicanos el 'ayuno’ de CS”. Excélsior, 8 de marzo de 1995, p. 1 y 34.

Fuentes, Carlos (1995). "Salinas versus Zedillo: las faldas de la Coatlicue". La Jornada, 7 de marzo de 1995 , p. 14-15.

García, Gastón (1995). "El presidente y el ex presidente”. Excélsior, 3 de marzo de 1995, p.1 y 10.

García, León (1995). "Nada cambió, el que cambió es Salinas". Excélsior, 4 de marzo de 1995, p. 7 y 8.

Garduño, Roberto y Carrizales, David (1995). "Seis horas tardó Salinas para decidirse a retirar su ayuno". La Jornada, 5 de marzo de 1995, p. 10.

Garza, Homero de la (1995). "Otra personalidad". El Sol de México, 7 de marzo de 1995, sec. A, p. 8 y 18.

González de la Garza, Mauricio (1995). "Mauricio dice. ¿Y Pedro Aspe?”. El Sol de México, 9 de marzo de 1995, sec. A, p. 9.

Granados Chapa, Miguel (1995). "Juicio a Salinas". Reforma, 5 de marzo de 1995, p. 6.

Guarneros, Fabiola (1995). "En Cuaresma, todos pueden ayunar; sería válido el de CSG: R. Godínez". El Universal, 4 de marzo de 1995, p. 17.

Hernández, Anabel y Méndez, Rosa (1995). "Demandan expulsar del PRI al salinismo”. Reforma, 2 de marzo de 1995, p. 7.

Hernández, Rogelio (1995). "Comedia de debilidades". El Universal, 8 de marzo de 1995, p. 7.

Herrera, Ignacio (1995). "Los ex presidentes, obligados a tener mesura: Palacios A". Excélsior, 4 de marzo de 1995 , p. 4 y 29.

Ícaro (1995). "Fax urgente". El Sol de México, 4 de marzo de 1995, sec. A, p.1.

Labastida, Jaime (1995). "Rompimiento político, no cabe duda. Un chantaje". Excélsior, 4 de marzo de 1995, p. 1 y 10.

La Jornada (1995a). "Atender el fondo, no las formas". La Jornada, 4 de marzo de 1995, p. 2.

La Jornada (1995b). "Guardar silencio, norma de los ex presidentes”. La Jornada, 4 de marzo de 1995 , p. 8.

La Jornada (1995c). "Más allá de Salinas”. La Jornada, 9 de marzo de 1995, p. 8.

EntreDiversidades. Revista de Ciencias Sociales y Humanidades, Vol. 8, Núm. 2 (17), julio-diciembre 2021. Páginas: 77-98 ISSN-e: 2007-7610. https://doi.org/10.31644/ED.V8.N2.2021.A04 
Loret de Mola, Rafael (1995). "Piense... El ex presidente”. Excélsior, 4 de marzo de 1995, p. 5 y 12. Manzanilla Schaffer, Víctor (1995). “¡Vaya Gandhi!”. El Universal, 4 de marzo de 1995, p. 7 y 10.

Martínez, Fabiola (1995). “Irracional' la huelga de hambre de Salinas: ANIT”. El Sol de México, 4 de marzo de 1995, sec. A, p. 2.

Mejía, Gerardo, et al. (1995). "Cuestionan ayuno". Reforma, 3 de marzo de 1995, p. 5.

Mejido, Manuel (1995a). "Alto poder”. El Sol de México, 4 de marzo de 1995, sec. A, p.19.

Mejido, Manuel (1995b). "Los grandes días del 95. Las nuevas reglas”. El Sol de México, 9 de marzo de 1995, sec. A, p. 6.

Mena, Alberto (1995). "Unánime condena en la ALDF de la oposición a Carlos Salinas". El Sol de México, 4 de marzo de 1995, sec. A, p. 15.

Méndez, Mario (1995). "Quién fue el culpable”. Excélsior, 6 de marzo de 1995, p. 7.

Michel Narváez, Jesús (1995). “¿Dignidad personal a costa de la del país?... Soberbia”. El Sol de México, 7 de marzo de 1995, sec. A, p. 9 y 18.

Moiron, Sara (1995). "Cuando ocurre lo increíble”. El Sol de México, 8 de marzo de 1995, A, p. 6 у 18.

Morales, Rodrigo (1995). “Temprana exoneración”. La Jornada, 6 de marzo de 1995, p. 7.

Morales, Sergio (1995a). "México requiere nuevos consensos políticos, no rupturas: Muñoz Ledo”. El Sol de México, 4 de marzo de 1995, sec. A, p. 14.

Morales, Sergio (1995b). "Muestra Salinas inmadurez política, opina A. Dimas". El Sol de México, 5 de marzo de 1995, sec. A, p. 15.

Morales, Sergio (1995c). "Solicitan líderes panistas objetividad y prudencia para estabilizar el país”. El Sol de México, 4 de marzo de 1995, sec. A, p. 14.

Moya, Rafael (1995). "Razones y sinrazones de Salinas". El Universal, 6 de marzo de 1995, p. 7.

Musacchio, Humberto (1995). "Los cien días de Zedillo". Reforma, 7 de marzo de 1995, p. 7.

Navarreto, Alberto y Ortiz, Irma (1995). "Le exigen dejar su actitud irresponsable". Excélsior, 5 de marzo de 1995, p. 1 y 28.

Noriega, Roberto (1995). "Piden partidos responsabilidad a CSG al responder sobre su mandato". El Sol de México, 4 de marzo de 1995, sec. A, p. 15.

Ortiz, Alicia, Carmen Álvarez y Guadalupe Irízar (1995). "Ecos del ayuno”. Reforma, 4 de marzo de 1995 , p. 6.

Palacios, José (1995). "Silencio, pide el PAN a Salinas; que declare lo que sepa: PRD y PVEM". El Universal, 5 de marzo de 1995, p. 17.

Pavón, Salvador, Aida Ramírez y Juan Moreno (1995). "Anuncia el PRI una 'inminente' depuración de sus cuadros". El Sol de México, 5 de marzo de 1995, sec. A, p. 15.

Pereztrejo, Sergio (1995). "Exculpan los ex Subprocuradores a Carlos Salinas en el Caso Colosio”. El Sol de México, 5 de marzo de 1995, sec. A, p. 17.

Proceso (1995). "Con su ayuno Salinas forzó la negociación y en su baluarte de Monterrey denuncia 'traiciones, deslealtades y cobardía”. Proceso, 4 de marzo, p. 5.

Ramírez, Lucero, Ella Gajeda y Ángeles Ruiz (1995). "No crear más confusión, piden gobernadores al ex presidente". El Universal, 5 de marzo de 1995, p. 1 y 14.

Rascón, Marco (1995). "El cuento de San Bernabé”. La Jornada, 6 de marzo, p. 8.

EntreDiversidades. Revista de Ciencias Sociales y Humanidades, Vol. 8, Núm. 2 (17), julio-diciembre 2021. Páginas: 77-98 ISSN-e: 2007-7610. https://doi.org/10.31644/ED.V8.N2.2021.A04 
Reforma (1995). "Rechazan priístas una ruptura política”. Reforma, 2 de marzo, p. 6.

Reyes, Martín (1995). "La insoportable pérdida del poder". El Universal, 4 de marzo, p. 1 y 12.

Rodríguez, Carola (1995). "Del arca de Noé. Nueva etapa”. El Sol de México, 4 de marzo de 1995, sec. A, p. 8.

Rodríguez, Francisco (1995a). “Índice político”. El Sol de México, 5 de marzo de 1995, sec. A, p. 14.

Rodríguez, Francisco (1995b). "Índice político”. El Sol de México, 8 de marzo de 1995, sec. A, p. 6.

Rodríguez, Rosa (1995). "Censura Muñoz Ledo la actitud del ex mandatario". La Jornada, 4 de marzo de 1995 , p. 8.

Romero, Ismael (1995). "Reacción excesiva de Salinas ante especulaciones: AN". La Jornada, 4 de marzo de 1995 , p. 8.

Romero, Javier (1995). "Calles sí pretendió venganza y hubo el riesgo de guerra civil". Excélsior, 8 de marzo de 1995, p. 1 y 28.

Samaniego, Fidel (1995). "Historias, voces, susurros...". El Universal, 4 de marzo de 1995, p. 8.

Sánchez, Jaime (1995). "Por el estado de derecho". Reforma, 4 de marzo de 1995.

Sodi de la Tijera, Demetrio (1995). "Con la vara que mides...". La Jornada, 10 de marzo de 1995 , p. 8.

Tavarés, Max (1995). "Concluyó CSG su ayuno; sus demandas serán satisfechas”. El Sol de México, 5 de marzo de 1995, sec. A, p. 1 y 16.

Torres, Rubén (1995). "Condenan líderes católicos campaña de CSG en medios de comunicación”, en El Sol de México, 4 de marzo de 1995, sec. A, p. 2.

EntreDiversidades. Revista de Ciencias Sociales y Humanidades, Vol. 8, Núm. 2 (17), julio-diciembre 2021. Páginas: 77-98 ISSN-e: 2007-7610. https://doi.org/10.31644/ED.V8.N2.2021.A04 